\title{
Erratum to: On the geological availability of germanium
}

\author{
Max Frenzel • Marina P. Ketris • Jens Gutzmer
}

Published online: 19 January 2014

(C) Springer-Verlag Berlin Heidelberg 2014

\section{Erratum to: Miner Deposita}

DOI 10.1007/s00126-013-0506-Z

The original version of this article inadvertently contained a mistake. All numbers referring to the recoverable amounts of germanium hosted by zinc ores, as stated in tables 6 and 9 as well as the main text and abstract of this publication, should be corrected upward by division through 0.67 . This correction reflects the fact that reserve/resource data given by the USGS refer to contained zinc metal, while germanium concentrations in the literature refer to sphalerite (zinc sulphide, $\mathrm{ZnS}$ ) which contains only up to $67 \mathrm{wt} . \%$ zinc.

The online version of the original article can be found under at http://dx.doi. org/10.1007/s00126-013-0506-z.

M. Frenzel $(\bowtie) \cdot J$. Gutzmer

Helmholtz-Institute Freiberg, Halsbrücker Str. 34, 09599 Freiberg,

Germany

e-mail: m.frenzel@hzdr.de

\section{P. Ketris}

Institute of Geology, Komi Scientific Center, Ural Branch of the

Russian Academy of Sciences, Morozova st., 100, ap. 49,

167023 Syktyvkar, Russia

\section{J. Gutzmer}

Institute for Mineralogy, University of Technology Bergakademie

Freiberg, Brennhausgasse 14, 09599 Freiberg, Germany 